\title{
A Decision Model for Information Systems Outsourcing: Using a Multicriteria Method
}

\author{
Jian-Jun Wang ${ }^{1}$, Zheng-Kui Lin $^{2}$ and Hao Huang ${ }^{3}$ \\ ${ }^{1}$ School of Management, Dalian University of Technology, Dalian 116024, P.R.China \\ ${ }^{2}$ School of Computer Science \& Technology, Dalian Maritime University, Dalian 116026, P.R.China \\ ${ }^{3}$ School of Economic and Management, Beihang University, Beijing 100083, P.R.China
}

\begin{abstract}
An ever-increasing trend in today's firms is to exploit outsourcing for those information systems (IS) functions deemed to be outside the company's core competence. Given the multi-attribute nature of IS outsourcing decision, this paper argues that five factors, including, strategy, economics, risk, environment and quality, should be considered for IS outsourcing decisions, and proposes the use of analytic hierarchy process (AHP) and improved ELECTREIII as aids in making IS outsourcing decisions. The AHP is used to analyze the structure of the outsourcing problem and determine weights of the criteria, and the improved ELECTREIII method is used for final ranking. It shows by means of an application that the hybrid method is very well suited as a decision-making tool for the IS outsourcing decision. Finally, potential issues for future research are presented.
\end{abstract}

Keywords: Information systems outsourcing, Multiple criteria analysis, AHP, ELECTREIII

\section{Introduction}

Information systems (IS) outsourcing can be defined as "a significant contribution by external vendors in the physical and/or human resources associated with the entire or specific components of the IS infrastructure in the user organization"[1]. IS outsourcing is a growing phenomenon in a wide variety of industries. According to the Gartner Group, overall spending in information technology (IT) outsourcing reached $\$ 177$ billion in 2003, and it is predicted to rise to $\$ 236$ billion in 2007(Oh, 2005). Yet in many cases, outsourced IS projects have failed. For example, in one study, IS managers reported only a 33\% satisfaction with outsourced IS services, as compared with a satisfaction rate of $70 \%-80 \%$ for outsourced non-IS services [2]. Wrong IS outsourcing decision is one of critical reasons which cause the high IS outsourcing failure [3]. Therefore, the scientific IS outsourcing decision process is very important to increase the success rate of outsourcing. The problem of how to scientifically make the IS outsourcing decisions tends to be an important issue facing organizations in today's rapidly changing business environment [4].

Business practitioners recognize that IS outsourcing is one of the many tools in their toolkit to design and manage their business and potentially has a place in most strategic plans. Although there is a wealth of academic literature examining outsourcing, it generally addresses the decision whether or not to outsource: the go/no go choice. There is little academic literature that address the IS outsourcing decision in a quantitative way. This paper will apply a hybrid of analytic hierarchy process (AHP) and improved
ELECTRE III methods to the "IS outsourcing decision" in an effort to demonstrate one quantitative approach to this complex decision.

The remainder of this paper is organized into five sections. Section 2 presents a brief literature review of the existing decision models related to the IS outsourcing decision. Section 3 will briefly describe the two proposed methodologies. In section 4 we argue five factors proposed as the principal criteria for outsourcing decision. In Section 5 a description of proposed methodology is followed by an application. In Section 6, we present our conclusions and future research.

\section{Literature Review}

A number of decision frameworks appear in academic literature to support the outsourcing decision-making process. Lacity, Willcocks and Feeny (1996) argued that deciding the outsourcing of IT activities just by strategic or commodities was fallacious and senior executives might mistakenly classify all IS activities as commodities. Therefore, they presented a 2x2 decision matrix guiding the selection of outsourcing candidates based on the business, economic, and technical factors[5].

Venkatraman (1997) viewed information technology as a portfolio of IS elements that were cost centers, service centers, investment centers and profit centers (which are collectively referred to as an IS “value centers”). His focus on "four independent sources of value from IS resource" is useful for identifying IS elements that might be considered for outsourcing [6]. 
Yang and Huang (2000) argued that five factors, including management, strategy, economics, technology and quality, should be considered for outsourcing decision, then they used the analytic hierarchy process (AHP) method to help users in structuring the outsourcing problems[7].

Roy and Aubert (2002) presented an IT outsourcing decision model based on the resource theory[8]. Hsu et al (2004) analyzed the IS outsourcing decision problems by case-based reasoning (CBR) method[9]. Aubert et al [2004] proposed an IT outsourcing decision model relied on transaction costs and incomplete contracts theories[10].

According to the above-mentioned literature, researchers put so many outsourcing decision strategies and determinants to practitioners, but current practice remains in the stage of conceptual discussion as to how to outsource the IS activities. Furthermore, only the AHP method offers a quantitative magnitude for judgment among these strategies and determinants. But AHP approach has the disadvantage that the number of pairwise comparisons to be made, may become very large (more specifically: $n(n-1) / 2)$. Another critical disadvantage of the AHP method is that compensation between good scores on some criteria and bad scores on other criteria can occur. Other strategies or determinants, for instance, decision matrix, transaction cost or CBR method, are too narrow to help the practitioners determine if their systems could be outsourced or to examine the priorities among many potential IS outsourcing projects. Ineffective outsourcing activities, derived from improper strategy or method, would lead to loss core competencies and capabilities, exposure to unexpected risk and business failures.

Facing the problem of how to decide the priority of those IS which have been decided to outsource, we propose a hybrid multi-criteria decision method for the IS outsourcing decision making. We shall use the AHP method to analyze the structure of the outsourcing problem and determine the weights of criteria, and use the improved ELECTRE III method for final ranking. The purpose of this work is to offer a quantitative decision model that can help practitioners set priority and reap the most benefits from outsourcing.

\section{The AHP and Electre III Method}

\subsection{The AHP Method}

The AHP, developed by Saaty (1980)[11], is a technique for considering data or information about a decision in a systematic manner [12]. The AHP mainly addresses how to solve decision problems with uncertainty and with multiple criteria characteristics. It is based on three principles: first, constructing the hierarchy; second, priority setting, and third, logical consistency.

\subsubsection{Construction the hierarchy}

A complex decision problem, centered round measuring contributions to an over objective or focus, is structured and decomposed into sub-problems (sub-objectives, criteria, alternatives, etc), within hierarchy.

\subsubsection{Priority setting}

The relative "priority" given to each element in the hierarchy is determined by comparing pairwise the contribution of each element at a lower level in terms of the criteria (or elements) with a causal relationship exists. In AHP multiple paired comparisons are based on a standardized comparison scale of nine levels (see Table 1, Saaty 1980).

Table 1. Scale of Relative Importance

\begin{tabular}{cc}
\hline $\begin{array}{c}\text { Intensity of impor- } \\
\text { tance }\end{array}$ & Definition \\
\hline 1 & Equal importance \\
2 & Weak \\
3 & Moderate importance \\
4 & Moderate plus \\
5 & Strong importance \\
6 & Strong plus \\
7 & Very strong or demon- \\
8 & strated importance \\
9 & Very, very strong \\
\hline
\end{tabular}

Let $C=\left\{C_{j} \mid j=1,2, \cdots, n\right\}$ be the set of criteria. The result of the pairwise comparison on n criteria can be summarized in a $(n \times n)$ evaluation matrix $A$ in which every element $a_{i j}$ is the quotient of weights of the criteria, as shown in (1).

$$
A=\left(a_{i j}\right),(i, j=1, \cdots, n)
$$

The relative priorities are given by the right eigenvector $(w)$ corresponding to the largest eigenvector $\left(\lambda_{\max }\right)$, as shown in (2).

$$
A w=\lambda_{\max } w
$$

In case the pairwise comparisons are completely consistent, the matrix $A$ has rank 1 and $\lambda_{\max }=n$. In that case, weights can be obtained by normalizing any of the rows or columns of matrix $A$.

The procedure described above is repeated for all subsystems in the hierarchy. In order to synthesize the various priority vectors, these vectors are weighted with the global priority of the parent criteria and synthesized. This process starts at the top of the hierarchy. As a result, the overall relative priority to be given to the lowest level elements is obtained. These overall, relative priorities indicate the degree to which the alternatives contribute to the focus. These priorities represent a synthesis of the local priorities, and reflect an evaluation process that permits to integrate the perspectives of the various stakeholders involved [13]. 


\subsubsection{Consistency check}

A measure of consistency of the given pairwise comparison is needed. The consistency is defined by the relation between the entries of $\mathrm{A}: a_{i j} \cdot a_{j k}=a_{i k}$. The "consistency index" (CI) is given by (3).

$$
\mathrm{CI}=\left(\lambda_{\max }-n\right) /(n-1)
$$

The final consistency ratio (CR), on the basis of which one can conclude whether the evaluations are sufficiently consistent, is calculated as the ratio of the consistency index (CI) and the random consistency index (RI), as indicated in (4). The number 0.1 is the accepted upper limit for CR. If the final consistency ratio exceeds the number, the evaluation procedure has to be repeated to improve consistency. The measurement of consistency can be used to evaluate the consistency of decision makers as well as the consistency of all the hierarchy.

$$
\mathrm{CR}=\mathrm{CI} / \mathrm{RI}
$$

\subsection{The ELECTRE III Method}

\subsubsection{The normal ELECTRE III method}

ELECTREIII method is a non-compensatory, MCDM technique. It uses various mathematical functions to indicate the degree of dominance of one alternative or group of alternatives over the remaining ones. It also facilitates comparisons between alternative schemes by assigning weights to decision criteria. The outranking relationships between alternatives are constructed and exploited eventually.

A discrete multiple criteria decision making problem is usually formulated by a set of alternatives $X=\left\{X_{1}, X_{2}, \cdots ; X_{h}\right\}$, a set of criteria $C=\left\{c_{1}, c_{2}, \cdots, c_{m}\right\}$ and a set of functions $G=\left\{g_{1}, g_{2}, \cdots, g_{m}\right\}$. The real-valued functions defined on the set $X$ so that $g_{l}\left(x_{j}\right)$ represents the performance of the alternative $X_{j}$ on the criterion $c_{l}$. Without loss of generality we assume that all the objective functions are to be maximized.

A pseudo-criterion is a preference model including three different thresholds: a preference threshold $p_{l}\left(g_{l}\left(x_{j}\right)\right)$, an indifference threshold $q_{l}\left(g_{l}\left(x_{j}\right)\right)$ and a veto threshold $v_{l}\left(g_{l}\left(x_{j}\right)\right)$ for each criterion $C=\left\{c_{1}, c_{2}, \cdots, c_{m}\right\}$. These thresholds may be constants, linear or affine functions of $g_{l}\left(x_{j}\right)$ in the form [14].

$$
p_{l}\left(g_{l}\left(x_{j}\right)\right)=\alpha_{p, l}+\beta_{p, l} g_{l}\left(x_{j}\right)
$$

and $q_{l}\left(g_{l}\left(x_{j}\right)\right)=\alpha_{q, l}+\beta_{q, l} g_{l}\left(x_{j}\right)$

For every criterion $c_{l}$, the preference and indifference threshold model is as follows. $x_{i}$ is preferred to $x_{j}$ if $g_{l}\left(x_{i}\right) \succ g_{l}\left(x_{j}\right)+p_{l}\left(g_{l}\left(x_{j}\right)\right)$

$x_{i}$ is weakly preferred to $x_{j}$ if

$g_{l}\left(x_{j}\right)+q_{l}\left(g_{l}\left(x_{j}\right)\right) \prec g_{l}\left(x_{i}\right) \leq g_{l}\left(x_{j}\right)+p_{l}\left(g_{l}\left(x_{j}\right)\right)$, and $x_{i}$ is indifferent to $x_{j}$ if

$g_{l}\left(x_{j}\right)+q_{l}\left(g_{l}\left(x_{j}\right)\right) \geq g_{l}\left(x_{i}\right)$ and

$g_{l}\left(x_{i}\right)+q_{l}\left(g_{l}\left(x_{i}\right)\right) \geq g_{l}\left(x_{j}\right)$

Where $p_{l}\left(g_{l}\left(x_{j}\right)\right)$ and $q_{l}\left(g_{l}\left(x_{j}\right)\right)$ are preference and indifference thresholds, respectively and $p_{l}\left(g_{l}\left(x_{j}\right)\right) \succ q_{l}\left(g_{l}\left(x_{j}\right)\right) \succ 0$. Weak preference is supposed to describe the decision maker's hesitation between indifference and preference.

In ELECTRE III method, one considers an outranking degree $S\left(x_{i}, x_{j}\right)$ describing the outranking credibility of $x_{i}$ over $x_{j}$ taking its values between 0 and 1 . The value of $S\left(x_{i}, x_{j}\right)$ is defined based on so-called concordance and discordance indices. A concordance index $C\left(x_{i}, x_{j}\right)$ is computed for each pair of alternatives $\left(x_{i}, x_{j}\right)$ by

$$
C\left(x_{i}, x_{j}\right)=\frac{1}{w} \sum_{l=1}^{m} w_{l} c_{l}\left(x_{i}, x_{j}\right)
$$

Where $w_{l}(l=1, \cdots, m)$ is the weight of each criterion, and

$$
\begin{gathered}
w=\sum_{l=1}^{m} w_{l} \\
c_{l}\left(x_{i}, x_{j}\right)=\left\{\begin{array}{cc}
1 & g_{l}\left(x_{i}\right)+q_{l}\left(g_{l}\left(x_{i}\right)\right) \geq g_{l}\left(x_{j}\right) \\
0 & g_{l}\left(x_{i}\right)+p_{l}\left(g_{l}\left(x_{i}\right)\right) \leq g_{l}\left(x_{j}\right) \\
\frac{p_{l}\left(g_{l}\left(x_{i}\right)\right)+g_{l}\left(x_{i}\right)-g_{l}\left(x_{j}\right)}{p_{l}\left(g_{l}\left(x_{i}\right)\right)-q_{l}\left(g_{l}\left(x_{i}\right)\right)} & \text { otherwise }
\end{array}\right.
\end{gathered}
$$

A discordance index $d_{l}\left(x_{i}, x_{j}\right)$ is defined for each criterion $C_{l}$ by

$$
d_{l}\left(x_{i}, x_{j}\right)=\left\{\begin{array}{c}
1 \quad g_{l}\left(x_{i}\right)+v_{l}\left(g_{l}\left(x_{i}\right)\right) \leq g_{l}\left(x_{j}\right) \\
0 \quad g_{l}\left(x_{i}\right)+p_{l}\left(g_{l}\left(x_{i}\right)\right) \geq g_{l}\left(x_{j}\right) \\
\frac{g_{l}\left(x_{j}\right)-g_{l}\left(x_{i}\right)-p_{l}\left(g_{l}\left(x_{i}\right)\right)}{v_{l}\left(g_{l}\left(x_{i}\right)\right)-p_{l}\left(g_{l}\left(x_{i}\right)\right)} \text { otherwise }
\end{array}\right.
$$

where $p_{l}\left(g_{l}\left(x_{i}\right)\right)$ is the preference threshold value and $v_{l}\left(g_{l}\left(x_{i}\right)\right)$ is the veto threshold value of each $c_{l}$ and $v_{l}\left(g_{l}\left(x_{i}\right)\right) \succ p_{l}\left(g_{l}\left(x_{i}\right)\right)$. 
Finally, the degree of outranking is defined by

$S\left(x_{i}, x_{j}\right)=\left\{\begin{array}{c}C\left(x_{i}, x_{j}\right) \quad d_{l}\left(x_{i}, x_{j}\right) \leq C\left(x_{j}, x_{j}\right) \quad \forall l \\ C\left(x_{i}, x_{j}\right) \bullet \prod_{l \in J\left(x_{i}, x_{j}\right)} \frac{1-d_{l}\left(x_{i}, x_{j}\right)}{1-C\left(x_{i}, x_{j}\right)} \quad J\left(x_{i}, x_{j}\right)\end{array}\right.$

where $J\left(x_{i}, x_{j}\right)$ is the set of criteria for which $d_{l}\left(x_{i}, x_{j}\right) \succ C\left(x_{i}, x_{j}\right)$. The complete set of outranking degree is assembled as shown in the following credibility matrix $\boldsymbol{S}$.

$$
\boldsymbol{S}=\left[\begin{array}{cccc}
S\left(x_{1}, x_{1}\right) & S\left(x_{1}, x_{2}\right) & \cdots & S\left(x_{1}, x_{n}\right) \\
S\left(x_{2}, x_{1}\right) & S\left(x_{2}, x_{2}\right) & \cdots & S\left(x_{2}, x_{n}\right) \\
\vdots & \vdots & \vdots & \vdots \\
S\left(x_{n}, x_{1}\right) & S\left(x_{n}, x_{2}\right) & \cdots & S\left(x_{n}, x_{n}\right)
\end{array}\right]
$$

The ranking of the decision alternatives in ELECTRE III is carried out by a distillation procedure, where the alternatives are ranked based on their qualification from the best to the worst (descending distillation process) and from the worst to the best (ascending distillation process).The final partial order of the alternatives is built based on these two complete orders. The descending distillation process is as follows.

Let $\lambda=\max _{x_{i}, x_{j} \in X} S\left(x_{i}, x_{j}\right)$. Determine a "credibility value" such that only values of $S\left(x_{i}, x_{j}\right)$ that are sufficiently close to $\lambda$ are considered; that is, $\lambda-s(\lambda)$. Thus if $\lambda=1$, let $s(\lambda)=0.15$. Define the matrix $\boldsymbol{T}$ as:

$$
\boldsymbol{T}\left(x_{i}, x_{j}\right)= \begin{cases}1 & \text { if } S\left(x_{i}, x_{j}\right) \succ \lambda-s(\lambda) \\ 0 & \text { otherwise }\end{cases}
$$

Further, define the qualification of each alternative - $Q\left(x_{i}\right)$ - as the number of alternatives that are outranked by $X_{i}$ minus the number of alternatives which outrank $x_{i} \cdot Q\left(x_{i}\right)$ is simply the row minus the column sum of the matrix $\boldsymbol{T}$. The set of alternatives having the largest qualification is the first distillate of $D_{1}$. If $D_{1}$ contains only one alternative, repeat the previous procedure with $X \backslash D_{1}$.Otherwise, apply the same procedure inside $D_{1}$. If distillate $D_{2}$ contains only one alternative, the procedure is started in $D_{1} \backslash D_{2}$ (unless the set is empty); otherwise it is applied within $D_{2}$, and so on until $D_{1}$ is used up. The procedure is then repeated starting with $X \backslash D_{1}$. The outcome is the first preorder.
The ascending distillation is carried out in a similar fashion except that alternatives with the smallest (rather than the largest) qualification are retained first.

3.2.2. An improved ranking method for ELECTRE III The normal ranking of ELECTRE III requires an additional threshold to be introduced. The weakness of this handing is that the ranking of the alternatives depends on the size of this threshold for which there exists no "correct" value. Additionally, the final ranking is not complete.

Aiming at the ranking problems in ELECTRE III, we present a new ranking method by introducing three definitions - concordance credibility degree, discordance credibility degree and net credibility degree, into ELECTRE III method.

\section{Definitions}

The concordance credibility degree is defined by

$$
\Phi^{+}\left(x_{i}\right)=\sum_{x_{j} \in X} S\left(x_{i}, x_{j}\right), \quad \forall x_{i} \in X
$$

The concordance credibility degree is the measure of the outranking character of $X_{i}$ (how $X_{i}$ dominates all the other alternatives of $X$ )

The discordance credibility degree is defined by

$$
\Phi^{-}\left(x_{i}\right)=\sum_{x_{j} \in X} S\left(x_{j}, x_{i}\right), \quad \forall x_{i} \in X
$$

The discordance credibility degree gives the outranked character of $X_{i}$ (how $X_{i}$ is dominated by all the other alternatives of $X$ )

The net credibility degree is defined by

$$
\Phi\left(x_{i}\right)=\Phi^{+}\left(x_{i}\right)-\Phi^{-}\left(x_{i}\right), \quad \forall x_{i} \in X
$$

The net credibility degree represents a value function, where a higher value reflects a higher attractiveness of alternative $x_{i}$.

\section{Final ranking}

All the alternatives can be completely ranked by the net credibility degree.

\section{An application}

This application is based on a real-life case study where the ELECTRE III method was use to help choose route for Dublin port motorway [15].

The first credibility matrix in [15] is as follows: 
$\boldsymbol{S}_{1}=\left[\begin{array}{cccccccc} & \text { B2/B3 } & \text { B4 } & \text { B6 } & \text { B5/7it } & \text { B5/7bt } & \text { B5/7ht } & \text { B8 } \\ \text { B2/B3 } & - & 0.625 & 0.75 & 0.875 & 0.875 & 0.875 & 0.875 \\ \text { B4 } & 0.875 & - & 1 & 1 & 1 & 0.875 & 0.875 \\ \text { B6 } & 0.875 & 1 & - & 1 & 1 & 0.875 & 0.875 \\ \text { B5/7it } & 0.875 & 0.875 & 0.875 & - & 0.875 & 0.875 & 0.875 \\ \text { B5/7bt } & 0.875 & 1 & 1 & 1 & - & 0.875 & 0.875 \\ \text { B5/7ht } & 0.75 & 0.875 & 0.875 & 0.875 & 0.875 & - & 1 \\ \text { B8 } & 0.688 & 0 & 0 & 0 & 0 & 0 & -\end{array}\right]$

The final ranking based on the normal method is as follows [15]:

$$
\{\mathrm{B} 4, \mathrm{~B} 6, \mathrm{~B} 5 / 7 \mathrm{bt}\} \rightarrow\{\mathrm{B} 2 / \mathrm{B} 3, \mathrm{~B} 5 / 7 \mathrm{hb}\} \rightarrow\{\mathrm{B} 5 / 7 \mathrm{it}, \mathrm{B} 8\}
$$

With $\boldsymbol{S}_{1}$ and (12)-(14) leads to the final values of concordance credibility degree, discordance credibility degree and net credibility degree of alternatives in Table 2.

Table 2. Degrees of alternatives $\left(S_{1}\right)$

\begin{tabular}{lccc}
\hline & $\Phi^{+}$ & $\Phi^{-}$ & $\Phi$ \\
\hline B2/B3 & 4.875 & 4.938 & -0.063 \\
B4 & 5.625 & 4.375 & 1.25 \\
B6 & 5.625 & 4.5 & 1.125 \\
B5/7it & 5.25 & 4.75 & 0.5 \\
B5/7bt & 5.625 & 4.625 & 1 \\
B5/7ht & 5.25 & 4.375 & 0.875 \\
B8 & 0.688 & 5.375 & -4.687 \\
\hline
\end{tabular}
lows:

The final ranking based on the new method is as fol-

$$
\begin{aligned}
& \mathrm{B} 4 \rightarrow \mathrm{B} 6 \rightarrow \mathrm{B} 5 / 7 \mathrm{bt} \rightarrow \mathrm{B} 5 / 7 \mathrm{ht} \rightarrow \mathrm{B} 5 / 7 \mathrm{it} \\
& \mathrm{B} 5 / 7 \mathrm{it} \rightarrow \mathrm{B} 2 / \mathrm{B} 3 \rightarrow \mathrm{B} 8
\end{aligned}
$$

The second credibility matrix in [15] is as follows:

$$
\boldsymbol{S}_{2}=\left[\begin{array}{cccccccc} 
& \text { B2/B3 } & \text { B4 } & \text { B6 } & \text { B5/7it } & \text { B5/7bt } & \text { B5/7ht } & \text { B8 } \\
\text { B2/B3 } & - & 0.45 & 0.61 & 0.81 & 0.81 & & \\
\text { B4 } & 0.93 & - & 1 & 1 & 1 & 0.93 & 0.93 \\
\text { B6 } & 0.93 & 1 & - & 1 & 1 & 0.93 & 0.93 \\
\text { B5/7it } & 0.93 & 0.97 & 0.97 & - & 0.97 & 0.93 & 0.93 \\
\text { B5/7bt } & 0.93 & 1 & 1 & 1 & - & 0.93 & 0.93 \\
\text { B5/7ht } & 0.75 & 0.82 & 0.82 & 0.82 & 0.82 & - & 1 \\
\text { B8 } & 0.69 & 0 & 0 & 0 & 0 & 0 & -
\end{array}\right]
$$

The final ranking based on the normal method is as follows [15]:

$$
\{\text { B4,B6,B5/7it,B5/7bt }\} \rightarrow \text { B5/7ht } \rightarrow \text { B2/B3 } \rightarrow \text { B8 }
$$

With $\boldsymbol{S}_{2}$ and (12)-(14) leads to the final values of concordance credibility degree, discordance credibility degree and net credibility degree of alternatives in Table 3.

The final ranking based on the new method is as follows:

$$
\begin{aligned}
& \mathrm{B} 4 \rightarrow \mathrm{B} 6 \rightarrow \mathrm{B} 5 / 7 \mathrm{bt} \rightarrow \mathrm{B} 5 / 7 \mathrm{it} \rightarrow \mathrm{B} 5 / 7 \mathrm{ht} \\
& \mathrm{B} 5 / 7 \mathrm{ht} \rightarrow \mathrm{B} 2 / \mathrm{B} 3 \rightarrow \mathrm{B} 8
\end{aligned}
$$

From above comparison, the final ranking based on the new method is complete ranking, while the normal is partial ranking.

Table 3. Degrees of alternatives $\left(S_{2}\right)$

\begin{tabular}{lccc}
\hline & $\Phi^{+}$ & $\Phi^{-}$ & $\Phi$ \\
\hline B2/B3 & 4.29 & 5.16 & -0.87 \\
B4 & 5.79 & 4.24 & 1.55 \\
B6 & 5.79 & 4.4 & 1.39 \\
B5/7it & 5.7 & 4.63 & 1.07 \\
B5/7bt & 5.79 & 4.6 & 1.19 \\
B5/7ht & 5.03 & 4.53 & 0.5 \\
B8 & 0.69 & 5.52 & -4.83 \\
\hline
\end{tabular}

The normal ranking method of ELECTRE III suffers from the complicated ranking process, which requires an additional threshold to be introduced. The weakness of this handing is that the ranking of the alternatives depends on the size of this threshold for which there exists no "correct" value. Additionally, the normal ranking method also suffers from incomplete ranking result. Aiming at the ranking problems in ELECTRE III, the present research develops a new ranking method. Compare to the normal ranking method, the new ranking method is simple and ranking result is complete.

\section{Performance Criteria}

There have been a lot of attempts to find out all factors of outsourcing decision, but the problem has not been theoretically solved. The choice of factors has been selected in agreement with a group of experts and managers. Another group might have selected a somewhat different set of factors. Firms should select all factors which can affect organizations benefit as possible as they can. A careful examination of factors used before concludes that five dimensions, strategy, economics, risk, environment and quality, should be included.

\subsection{Strategy}

For strategy, firms need to focus on their core activities and outsource noncore activities. IS outsourcing allows management to focus available IS talent on important and strategic IT applications rather than the mundane and routine activities. The internal operations and outsourced operations should then work in unions striving to optimize flexibility and responsiveness to customer and internal needs, and minimize unnecessary paperwork and bureaucracy. In addition, the firms can make strategic alliance with vendors to make up the shortage of resources; resources include new technologies and professional workers. From strategic alliances, the firm even can develop and market new products. Other strategic consideration includes sharing risks and accelerating the time of product to market [5][7][16][17][18][19]. 


\subsection{Economics}

For economics, the major consideration of a firm is to reduce costs of information systems. Because the vendors have a better management skill as well as higher productivity per employee, the costs can be reduced. Meanwhile, Because of the scale of economics vendors have invested in the hardware, software and human resources, the cost can be reduced. Another consideration of economics is financial flexibility. Because of outsourcing, the facilities and employee would be transferred to the vendor side, which transform fixed costs into variable costs, resulting in increasing financial flexibility [7][9][20][21].

\subsection{Risk}

For risk, it is rare to experience opportunities in organizational life where the managerial actions taken to produce benefits are not associated with potential risks either. This is most certainly the case with IS outsourcing. The most prominent risks in outsourcing are information security concerns and loss of management control. Khalfan [2004] noted theses two factors were coupled with hidden costs in outsourcing [22].

If a labor union exists, a firm should first explore its negative effect before deciding to outsource, since outsourcing is accompanied with some possibility of layoffs. Companies often have to deal with low employee morale as a result of outsourcing, and low employee morale in turn affects productivity. It has been noted that often a large proportion of IT staff are laid off as a consequence of an outsourcing contract. This can cause a lot of disturbance in the client company.

Other risks that have to be dealt with include: loss of core competence, loss of internal technical knowledge, loss of flexibility, damaging the firm's innovative capability, increasing information services management complexity, etc [23][24]. As being the factors with benefits, these risks factors should not be ignored in outsourcing activities [25] [26].

\subsection{Environment}

Quinn and Hilmer [1994] indicated that environment factors such as market maturity, market depth, and the number of suppliers influences the level of outsourcing [16]. There are times when contestability explains market maturity; a contestable market means that while only a few firms can immediately provide the service now, many other firms are intending to provide the service if the price paid by the firm exceeds the average cost of vendors. In addition, the decision to outsource may be induced by imitative behavior among firms [27]. For example, Kodak's outsourcing decision made many other firms begin to consider IS outsourcing as a viable alternative [28].

\subsection{Quality}

For quality, because vendors may have access to more technological environments, have more qualified or more motivated personnel, provide a greater breadth of services, and simply be more committed than internal staff to making the alliance with the customer work well, outsourcing can improve the quality and services of the internal IS department. Therefore, good quality of service and good relationship are the significant success factors of outsourcing [7] [25[29].

\section{An Application}

Based on IS outsourcing decision problem presented in Section 1, an example is used to illustrate how the combined AHP and improved ELECTREIII model support decision maker on the IS outsourcing decision making.

\subsection{The Problem Faced}

A bookstore wants to outsource parts of IT functions, they think about the management and cost issues and want to know how to decide which systems should be outsourced first.

The candidate systems for outsourcing are facilities management (P1), development of internet homepage (P2), maintenance of the customer relationship management information system (P3), development of the supplier relationship management information system (P4), development and maintenance of the online transaction processing system (P5).

The leader of the task force is the vice president, while members include IS department manager, a senior engineer, business department manager, finance department manager, planning department manager and five professional consultants. The vice president convened a meeting to discuss this problem. After some discussion, they employ the hybrid of AHP and ELECTRE III methods in the decision process.

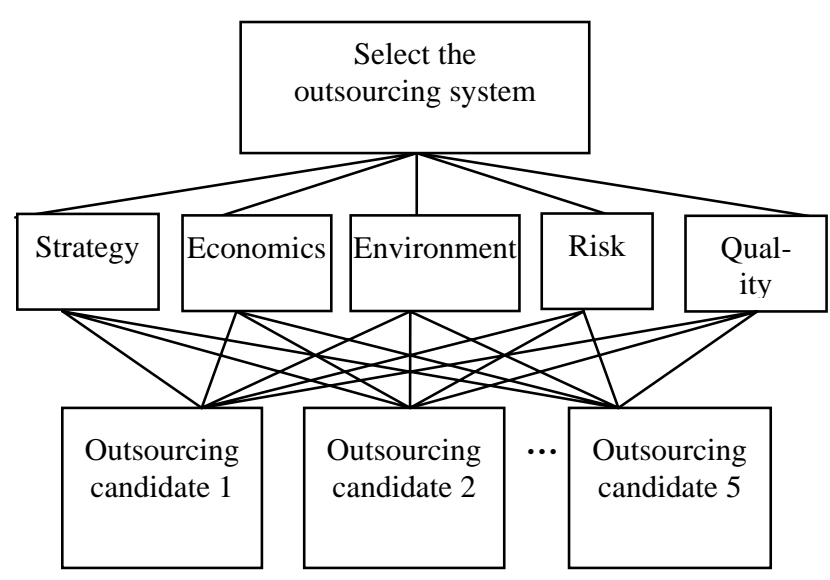

Figure 1. The Hierarchy Structure of the Problem

\subsection{Structure of the Problem}

After some debate, according to the AHP method, the 
task force depicts a hierarchy structure as shown in Figure 1.

\subsection{Determination of the Weights}

Following the computing method described in the AHP, experts began to compare the factors of the structure. After that, they got the square matrix as shown in Table 4 .

Table 4. The Square Matrix.

(C1- Strategy; C2- Economics; C3- Environment;C4Risk;C5- Quality)

\begin{tabular}{llllll}
\hline & C1 & C2 & C3 & C4 & C5 \\
\hline C1 & 1 & 3 & 4 & 2 & 4 \\
C2 & $1 / 3$ & 1 & 1 & $1 / 3$ & 1 \\
C3 & $1 / 4$ & 1 & 1 & $1 / 3$ & 1 \\
C4 & $1 / 2$ & 3 & 3 & 1 & 3 \\
C5 & $1 / 4$ & 1 & 1 & $1 / 3$ & 1 \\
\hline
\end{tabular}

According to (1)-(4), we got

$\lambda_{\text {max }}=5.0394$

$\mathrm{R} I=1.12$

$\mathrm{C} \mathrm{R}=0.0088<0.1$

$w=(0.41,0.11,0.10,0.28,0.10)$

\subsection{Evaluation of Alternatives}

All outsourcing candidates were evaluated by experts. According to the criteria of strategy, environment, risk and quality, a qualitative impact value is used, expressed on a qualitative scale (judgment on a series of ordered semantic values; each semantic value included in the set \{very weak, weak, common, good, very good $\}$ is associated with a numerical value $\{1,3,5,7,9\}$, that is used for the calculations.). The economics indicator is evaluated by the following formula:

Saving costs / Costs of in house development and maintenance (\%).A $5 \times 5$ matrix was produced, as shown in table 5 .

Table 5. Evaluation Matrix (C1- Strategy; C2Economics; C3- Environment;C4- Risk;C5- Quality)

\begin{tabular}{llllll}
\hline Criteria & C1 & C2 & C3 & C4 & C5 \\
Max/Min & Max & Max & Max & Min & Max \\
Weight & 0.41 & 0.11 & 0.10 & 0.28 & 0.10 \\
\hline P1 & 9 & 15 & 9 & 1 & 9 \\
P2 & 7 & 12 & 7 & 3 & 7 \\
P3 & 3 & 8 & 3 & 7 & 3 \\
P4 & 7 & 15 & 5 & 5 & 7 \\
P5 & 7 & 10 & 7 & 7 & 5 \\
\hline
\end{tabular}

\subsection{Final Ranking}

Before using the ELECTRE III method to calculate the indices, for each criterion's thresholds is defined (see table 6).

Table 6. The Thresholds of Each Criterion

\begin{tabular}{llll}
\hline & $q$ & $p$ & $v$ \\
\hline Strategy & 2 & 3 & 8 \\
Economics & 2 & 4 & 8 \\
Environment & 2 & 3 & 4 \\
Risk & 2 & 3 & 7 \\
Quality & 2 & 3 & 6 \\
\hline
\end{tabular}

According to (5)-(9), we get the outranking degree matrix $\boldsymbol{S}$ :

$$
\boldsymbol{S}=\left[\begin{array}{ccccc}
1 & 1 & 1 & 1 & 1 \\
0.94 & 1 & 1 & 0.94 & 1 \\
0 & 0 & 1 & 0.15 & 0 \\
0 & 1 & 1 & 1 & 1 \\
0.26 & 0.72 & 1 & 0.89 & 1
\end{array}\right]
$$

According to (12)-(14), we got the values of leaving, entering and net flows and the complete ranking of alternatives in table 7 and in figure 2.

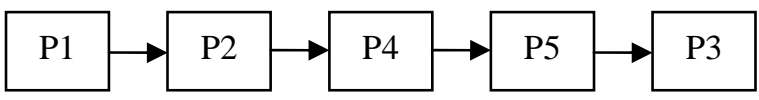

Figure 2. Final Ranking

The priorities for outsourcing the five IS are in the following order: facilities management (P1), development of internet homepage (P2), development of the supplier relationship management information system (P4), development and maintenance of the online transaction processing system (P5), maintenance of the customer relationship management information system (P3). If the bookstore want to outsource two IS activities first, we know that the facilities management and development of internet homepage would be outsourced.

Table 7. Values of Leaving, Entering and Net Flows

\begin{tabular}{cccc}
\hline & $\Phi^{+}$ & $\Phi^{-}$ & $\Phi$ \\
\hline P1 & 4 & 1.20 & 2.80 \\
P2 & 3.88 & 2.72 & 1.16 \\
P3 & 0.15 & 4 & -3.85 \\
P4 & 3 & 2.98 & -0.02 \\
P5 & 2.87 & 3 & -0.13 \\
\hline
\end{tabular}

\section{Conclusions and Future Researches}

IS outsourcing is emerging as a flexible and powerful 
management approach chosen by managers to achieve a wide range of tactical and strategic goals. Outsourcing firms benefit from cost savings, strategic fitness, improved management effectiveness, technology upgrade, and the service quality of IS. Moreover, one needs an operational decision model that can offer systematic steps and quantitative results to increase the precision of decision-making.

This study suggests a decision model for IS outsourcing adoption for management, and shows how it may be applied in a real decision process for IS outsourcing. This research also argues that firms need to consider more dimensions, including economics, strategy, risk, environment and quality factors. Meanwhile, we offer a decision model, which developed by AHP and improved ELECTRE III methods, to help the practitioners make better decisions. Our approach allows to deal with IS outsourcing project selection involving several conflicting performance criteria (qualitative as well quantitative). The proposed decision model can help practitioners analyze factors and attributes easily. Because it is a quantitative process, the practitioners can make better decisions and obtain better results from outsourcing.

While it has successfully developed the decision model for IS outsourcing, and with most research efforts, this study is not without limitations. First, the case study just based on a small firm. Second, the AHP and ELECTRE III methods also have their own limitations; such as, in order to get more professional results, the use of more advance form of AHP method would be desirable. In addition, the determinants in the decision model are not complete. Further studies need to include additional possible factors through a more extensive literature review and empirically investigation.

\section{Acknowledgements}

This work is partially supported by a grant from National Science Fund for Distinguished Young Scholars of China (No. 70725004).

The authors also thank the anonymous referees for improving the quality of the paper with their precious and careful remarks.

\section{REFERENCES}

[1] Loh, L., \& Venkatraman, N, "Determinants of information technology outsourcing: a cross-sectional analysis”, Journal of Management Information Systems, 1992, 9(1), 7-24.

[2] King, W.R, "Developing a sourcing strategy for IS: A behavioral decision process and framework", IEEE Transaction Engineering Management, 2001, 48(1), 15-24

[3] Wu, F., \& Li, H.Z, “The effect of knowledge man- agement on the successful outsourcing of IT/IS”, Science Research Management, 2004, 25(2), 82-87.

[4] Lee, Jae-N, “The impact of knowledge sharing, organizational capability and partnership quality on IS outsourcing success”, Information \& Management, 2001, 38, 323-335.

[5] Lacity, M.C., Willcocks, L.P., \& Feeny, D.F, “The value of IT sourcing”, Sloan Management Review, 1996, 37(3), 13-25.

[6] Venkatraman, N, "Beyond outsourcing: Management IT resources as a value center", Sloan Management Review, 1997, 38(3), 51-64.

[7] Yang, C., \& Huang, J, "A decision model for IS outsourcing”, International Journal of Information Management, 2000, 20(3), 225-239.

[8] Roy, V., \& Aubert, B, “A resources-based analysis of IT sourcing”, ACM SIGMIS Database, 2002, 33(2), 29-40.

[9] Hsu, C.I., Chiu. C., \& Hsu, P.L, "Predicting information systems outsourcing success using a hierarchical design of case-based reasoning”, Expert Systems with Application, 2004, 26(3), 435-441.

[10] Aubert, B.A., Riverd, S., \& Patry, M, “A transaction cost model of IT outsourcing”, Information \& Management, 2004, 41, 921-932.

[11] Saaty, T. L, The analytic hierarchy process. New York: McGraw Hill, 1980.

[12] Schniederjans M J, Garvin T. "Using the analytic hierarchy process and multi-objective programming for the selection of cost drivers in activity-based costing," European Journal of Operational Research, 1997, 100: 72-80.

[13] Macharis C, Springael J, De Brucher K, Verbeke A. "PROMETHEE and AHP: the design of operational synergies in multicriteria analysis. Strengthening PROMETHEE with ideas of AHP," European Journal of Operational Research, 2004, 153(2): 307-317.

[14] K. Miettinen, P. Salminen, "Decision-aid for discrete multiple criteria decision making problems with imprecise data”, European Journal of Operational Research, 1999, 119: 50-60.

[15] M. Rogers, M. Bruen, "Using ELECTRE III to choose route for Dublin fort motorway”, Journal of Transportation Engineering, 2000, 126(4): 313-326.

[16] Quinn, J.B., \& Hilmer, F.B, „Strategic outsourcing”, Sloan Management Review 1994, 35(4), 43-55.

[17] Quinn, J.B, “Strategic outsourcing”, Sloan Management Review, 1999, 40(4), 23-26.

[18] Gilley, K.M., \& Rasheed, A, "Making more by doing less: Analysis of outsourcing and its effects on firm performance”, Journal of Management, 2000, 26, 763-790.

[19] Avgerou, C., \& Cornford, T, Developing Information Systems: Concepts, Issues and Practice (2nd edn). Basingstoke: Macmillan; 1998. 
[20] McFarlan, F.W., \& Nolan, R.L, "How to manage an IT outsourcing alliance”, Sloan Management Review, 1995, 36(2), 9-23.

[21] Collins, J., Millen. R., \& Beamish, P, "Information systems outsourcing by large American industrial firms: Choice and impact”, Information Resources Management Journal, 1995, 8(1), 5-13.

[22] Khalfan, A.M, "Information security considerations in IS/IT outsourcing projects: a descriptive case study of two sectors" International Journal of Information Management, 2004, 24, 29-42.

[23] Bahli, B., Rivard, S, "Validating measures of information technology outsourcing risk factors", Omega, 2005, 33(2): 175-187.

[24] Osei-Bryson, K. Muata., Ngwenyama, O. K, "Managing risks in information systems outsourcing: An approach to analyzing outsourcing risks and structuring incentive contracts", European Journal of
Operational Research, 2006, 174(1): 245-264.

[25] Clark, T., Zmud, R., \& McCray, G, “The outsourcing of information services: transforming the nature of business in the information industry”, Journal of Information Technology, 1995, 10(4), 221-237.

[26] Earl, M.J, “The risks of outsourcing IT”, Sloan Management Review, 1996, 37(3), 26-32.

[27] Lacity, M.C., Herschheim,R., \& Willcocks, L, "Realizing outsourcing expectations”, Information Systems Management, 1994, 4, 7-18.

[28] Smith, M., Mitra, S., \& Narasimhan, S, “Information systems outsourcing: a study of pre-event firm characteristics", Journal of Management Information Systems, 1998, 15, 61-93.

[29] Grover, V., Joong, M., Cheon., \& Teng, J.T, “The effect of service qualify and partnership on the outsourcing of information systems functions”, Journal of Management Information Systems, 1996, 12(4), 89-116.

\section{AUTHORS’ BIOGRAPHIES}

Jian-Jun Wang completed his Ph.D. in Information Systems from Dalian University of Technology, P.R.China. He has been Assistant Professor at Dalian University of Technology. His main research fields are IS/IT outsourcing, service management and e-commerce. He is involved in many national research projects and he has published many research papers in refereed academic journals such as Computers \& Operations Research, Chaos, Solitons and Fractals, International Journal of Pure and Applied Mathematics, International Journal of Knowledge and Systems Sciences, etc. He served as a reviewer for a number of international refereed academic journals and refereed conferences. Email: drwangjj@dlut.edu.cn

Zheng-Kui Lin completed his Ph.D. in Management Science and Engineering from Dalian University of Technology, P.R.China. He has been Associate Professor at Dalian Maritime University. His main research fields are information systems and e-commerce. He is author of more than 10 articles published on national and international refereed journals. Email: dalianjx@163.com

Hao Huang is a Ph.D. candidate in School of Economic and Management at Beihang University, P.R.China. He works in the field of information management. Email: huang_hao98@yahoo.com.cn 
